\title{
Potential habitats versus functional habitats in a lowland braided river (Córdoba, Argentina)
}

\author{
Cristina M. Gualdoni*, Maricel F. Boccolini, Ana M. Oberto, Romina E. Principe, \\ Graciela B. Raffaini and Maria del Carmen Corigliano \\ Universidad Nacional de Río Cuarto, Departamento de Ciencias Naturales, X5804BYA Río Cuarto, Córdoba, Argentina
}

Received 30 September 2008; Accepted 24 April 2009

\begin{abstract}
The benthic community of a braided reach of a lowland river was studied with the aim to identify functional habitats through the assessment of potential habitats. Functional habitats were defined considering physical and biological characteristics. Three reaches of the Chocancharava River (Córdoba, Argentina) were selected and six potential habitats were sampled during high and low water periods. Hydraulic and environmental variables were also registered in each sampling occasion. Taxonomic composition, macroinvertebrate abundance, richness, diversity and evenness were estimated for each identified functional habitat. TWINSPAN analysis was applied separately for two data sets (high water and low water period). This analysis showed that samples of the low water period were mainly grouped in relation to three habitats units: vegetated habitats, unvegetated habitats and habitats related to bars. These three habitats were considered functional habitats. The whole biological and environmental data sets were ordinated by Canonical Correspondence Analysis (CCA) showing a significant relationship between benthic assemblages and environmental variables. This analysis grouped samples in relation to the functional habitats identified by TWINSPAN and indicated that the most influential environmental variables explaining the ordination were: current velocity, depth, substrate size and cover percent of rooted emergent macrophytes. Faunal composition determined by CCA for each functional habitat was in agreement with the results obtained by the Relative Preference Index (RPI). Factorial ANOVAs showed that abundance, taxonomic richness, diversity and evenness were different among the functional habitats and that the community attributes were influenced by the effect of the hydrological period and habitat. As the functional habitat approach provides useful tools in management and river rehabilitation the use of this methodology may allow to develop more appropriate restoration strategies to be applied in altered lowland reaches.
\end{abstract}

Key words: Benthos / macroinvertebrates / habitat / community structure / braided river

\section{Introduction}

The current expansion of anthropogenic activities and its effect on natural fluvial ecosystems calls for studies that provide a scientific basis to evaluate the ecological integrity of river systems. In addition, this information becomes essential to develop rehabilitation and conservation strategies. Stream habitat represents an essential component of river health, and can be used to evaluate the overall integrity of a fluvial ecosystem (Davies et al., 2000). Under this premise the fluvial habitats can be identified, characterized and classified at different spatial and temporal scales (Frissell et al., 1986; Amoros et al., 1987). The use of the spatial scale at the level of functional habitats (Harper et al., 1995) or mesohabitats (Armitage and Pardo, 1995;

\footnotetext{
* Corresponding author: cgualdoni@exa.unrc.edu.ar
}

Pardo and Armitage, 1997) for the assessment of fluvial ecological condition has increased in recent years. Although these concepts are basically the same, they were given different names since they were developed by two separate research groups (Kemp et al., 2000). The functional habitat concept links biological and physical characterization of the habitat (Harper et al., 1995; Buffagni et al., 2000). These habitat units are objectively defined, are made up of substrate or vegetation types and are identified as distinct by their invertebrate assemblages (Kemp et al., 2000).

The effectiveness of monitoring programs based on the mesohabitat approach strongly depends of the correct identification of the functional habitats (Buffagni et al., 2000). These habitat units are determined from potential habitats, which are recognizable from simple visual survey. Rivers have a wide variety of potential habitats 


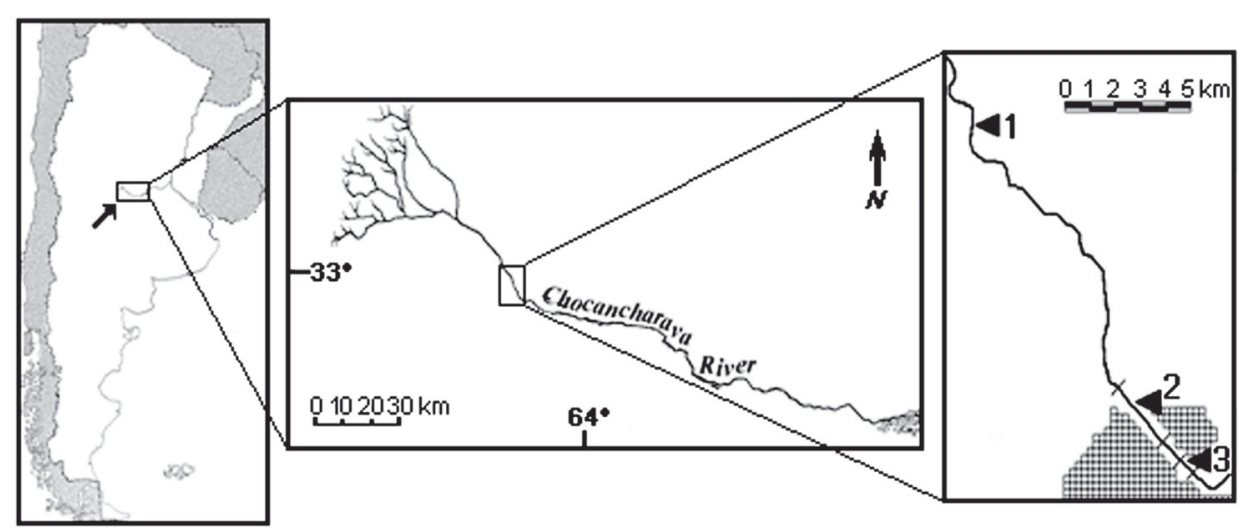

Fig. 1. Location of study sites in the Chocancharava River, Córdoba, Argentina.

with varying macroinvertebrate assemblages that tend to be overlapped. Consequently, it is difficult for stream ecologists to accurately identify discrete sampling units that can be perceived free from subjectivity and in the same manner by different operators.

A great deal of research has been done to identify and to characterize the available habitats to instream fauna in USA as well as in many European countries (Hawkins et al., 1993; Buffagni et al., 2000; Brunke et al., 2001; Halwas and Church, 2005) and more recently in streams of the neotropical region (Ramírez et al., 1998; Baptista et al., 2001; Velásquez and Miserendino, 2003; Principe et al., 2007). Most of this research was made in large lowland rivers with low gradients (Thomaz et al., 2007) or mountain streams with high to moderate gradients, where pools and riffles are the characteristic habitat units (Vadas and Orth, 1998; Brooks et al., 2005). Particularly, the functional habitat concept has been mainly tested in Europe, especially in lowland rivers (Buffagni et al., 2000). However, braided sand-bed rivers, widespread in temperate piedmont areas of South America have received little empirical documentation, at least from the ecological point of view. Braided rivers are very dynamic systems and their hydrology and geomorphology has been studied in order to understand their complexity (Tockner et al., 2006).

Braided rivers consist of a main channel with unstable bed and multiple channels coupled with mobile bars (Amoros et al., 1987; Baptist, 2001). This pattern increases the structural complexity of the channel and produce morphologic unit diversification. The morphologic units differ in their physical characteristics, mainly in flow velocity, depth and structure of the bed substrate. Thus, it is important to study the distribution and abundance of macroinvertebrates among different habitat units in a braided reach of a river-floodplain system in order to assess if potential habitats really constitute functional habitats. In this paper, we show the first results of the application of the functional habitat classification concept in a South American braided river. The objectives of our study were: (i) to define the potential habitats in a braided reach of the Chocancharava River; (ii) to determine if macroinvertebrate assemblages differ among the identified potentials habitats and thus to identify biologically meaningful functional habitats; and (iii) to describe each functional habitat both in terms of their biological and physical characteristics.

\section{Study area}

The present study was carried out in a 7 th order reach of the Chocancharava River in central Argentina. It is a medium size river and its headwaters are about 2300 m a.s.1. in Sierras de los Comechingones, Córdoba, Argentina. The river flows $400 \mathrm{~km}$ through agricultural land into the Carcarañá River, which belongs to ParanáPlata basin (Fig. 1). The study section is situated in a piedmont area, where the channel morphology is braided of low-sinuosity, with a sand-dominated bed and temporal mobile bars. The fluvial course occurs on sediments of alluvial origin with a high susceptibility to erosion (Degiovanni et al., 1995). Chocancharava River is a highly dynamic pluvial system. The rainy season has a maximum precipitation of $890 \mathrm{~mm}$ concentrated in the springsummer period (Degiovanni et al., 1995).

Three study sites were selected in this river section. Site 1 was located upstream of Río Cuarto city and sites 2 and 3 were urban reaches placed approximately $4 \mathrm{~km}$ and $5 \mathrm{~km}$ downstream of site 1 respectively. Biological quality has already been tested in this section of the river (Boccolini et al., 2005) and the three selected sites did not differ in multimetric indexes values, which considered structural attributes such as richness, composition and tolerance/intolerance. At each site, five potential habitats were determined using a preliminary visual estimation considering flow velocity, depth, aquatic vegetation and substratum granulometry. The selected habitats were: unvegetated secondary channels (uc), secondary channels with highly mobile substrate (mc), backwaters in bars (bb), channels in bars (cb) and vegetated secondary channels (vc). An additional potential habitat, a vegetated secondary channel in a calcrete river bank (cc), was identified in the site 1 (Fig. 2). The main channel of Chocancharava River in the study section does not provide suitable habitats to be colonized by resident biota due to the highly mobile substrate and high current velocity 


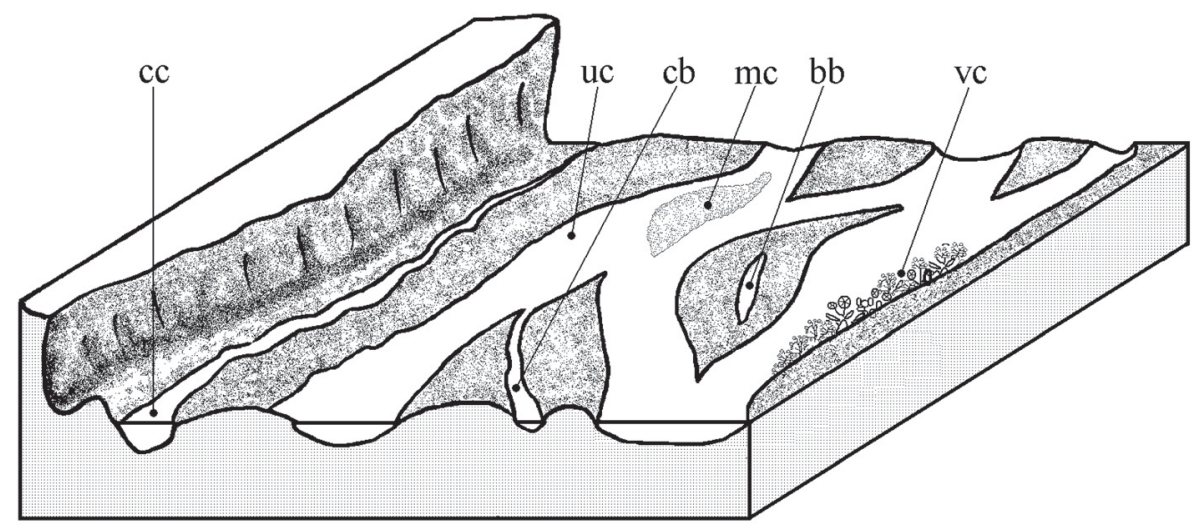

Fig. 2. Potential habitats of a piedmont reach in the Chocancharava River: unvegetated secondary channel (uc), secondary channel with highly mobile substrate (mc), backwater in bar (bb), channel in bar (cb) and vegetated secondary channel (vc) and vegetated secondary channel in a calcrete river bank (cc).

(Corigliano et al., 1987). Then the main channel was not included in the present study.

\section{Materials and methods}

\section{Field and laboratory methods}

Sampling was carried out in high (February-March) and low (August) water periods in 2003. At each potential habitat, three benthic random samples were collected using a Hess sampler (300 $\mu \mathrm{m}$ mesh size, $0.07 \mathrm{~m}^{2}$ area) and immediately fixed in 5\% formaldehyde for later sorting in laboratory. A total of 96 benthic samples were collected (3 replicates, 2 hydrological periods, 3 reaches, 5 habitat units and an additional habitat in site 1). Additionally, water depth and flow velocity were registered with a Global Flow Probe FP101-FP201 in three points randomly selected on each potential habitat and mean values were calculated. Bed-sediment samples were taken to measure substrate composition in the laboratory. Total percent cover of rooted emergent macrophytes was evaluated in situ by visual assessment in a transect along each potential habitat. Vegetation cover was assigned to a categorical value between 0 and 4 , where $0=$ $0 \%, 1=0-25 \%, 2=25-50 \% ; 3=50-75 \%$ and $4=75-$ $100 \%$. Aquatic vegetation is more abundant in areas close to the riverside and is mainly constituted by Alternanthera philoxeroides, Hydrocotyle bonariensis, Nasturtium officinale and Polygonum acuminatum. In the laboratory, sediment samples were sieved through different mesh sieves and were weighed to determine the substrate percentage composition according to Hynes (1970): pebble (16-64 mm), gravel $(4-16 \mathrm{~mm})$, coarse sand $(0.5-4 \mathrm{~mm})$, medium sand $(0.25-0.5 \mathrm{~mm})$, fine sand $(0.0625-0.25 \mathrm{~mm})$ and silt-clay $(<0.0625 \mathrm{~mm})$.

Macroinvertebrates were sorted under a stereomicroscope and a binocular microscope, preserved in $70 \%$ ethanol, identified, and counted. Identification was made at the lowest possible taxonomic level, generally genus or species, according to the knowledge of the Argentinean freshwater macroinvertebrate fauna (Lopreto and Tell, 1995; Fernández and Domínguez, 2001).

\section{Data analysis}

Composition, abundance, taxonomic richness, Shannon diversity and evenness were calculated for each sample. Species data of different potential habitats were classified by TWINSPAN (two way indicator species analysis) (Hill, 1979) to determine the functional habitats. TWINSPAN is a hierarchical divisive method of classification which uses taxa abundance as indicator of spatial and temporal variation in community composition. This technique has been a common statistical tool over the years to illustrate groupings of macroinvertebrate communities and is widely used in most prediction systems developed so far (see review in Gauch, 1982). TWINSPAN analysis has been used to classify functional habitats on the dataset from UK rivers (Harper et al., 1992) and from an Italian river dataset (Crosa and Buffagni, 1996; Buffagni et al., 2000). TWINSPAN is based on indicator species analysis, which provides a classification of samples based on their taxonomic composition outlining the indicator species pertaining to each dicotomic group division. We applied TWINSPAN to the abundance of all identified taxa in each hydrological period (pseudospecies cut levels were $0,2,5,10$ and 20). Initially, we used the total of 96 samples collected to carry out the analysis; however the resulting classification was extremely confusing. Then, in order to obtain more defined results, we performed TWINSPAN for two data sets separately: an analysis was performed with 48 samples from the high water period and the other with 48 samples from the low water period. Once we obtained the results of the classification, all the collected samples were assigned to the functional habitats defined by TWINSPAN.

Canonical Correspondence Analysis (CCA) was performed to relate changes in species abundance 
Table 1. Environmental variables (mean and standard deviation) and percentage categories of rooted emergent macrophytes in each potential habitat of the Chocancharava River. uc: unvegetated secondary channel; mc: secondary channel with highly mobile substrate; bb: backwater in bar; cb: channel in bar; vc: vegetated secondary channel; cc: vegetated secondary channel.

\begin{tabular}{|c|c|c|c|c|c|c|c|c|c|c|c|c|c|c|c|c|c|c|}
\hline \multirow[b]{3}{*}{ Environmental variables } & \multicolumn{18}{|c|}{ Potential habitats } \\
\hline & \multicolumn{3}{|c|}{$\mathrm{uc}$} & \multicolumn{3}{|c|}{$\mathrm{mc}$} & \multicolumn{3}{|c|}{$\mathrm{bb}$} & \multicolumn{3}{|c|}{$\mathrm{cb}$} & \multicolumn{3}{|c|}{$\mathrm{vc}$} & \multicolumn{3}{|c|}{$\mathrm{cc}$} \\
\hline & $x$ & \pm & sd & $x$ & \pm & $\mathrm{sd}$ & $x$ & \pm & $\mathrm{sd}$ & $x$ & \pm & $\mathrm{sd}$ & $x$ & \pm & sd & $x$ & \pm & $\mathrm{sd}$ \\
\hline Flow velocity $\left(\mathrm{m} . \mathrm{s}^{-1}\right)$ & 6.6 & \pm & 1.2 & 5.2 & \pm & 1.3 & 0.4 & \pm & 1.4 & 2.8 & \pm & 2.0 & 5.0 & \pm & 2.1 & 0.6 & \pm & 0.8 \\
\hline Depth (cm) & 18.7 & \pm & 7.0 & 10.8 & \pm & 5.1 & 3.2 & \pm & 5.8 & 6.1 & \pm & 3.7 & 18.3 & \pm & 11.6 & 8.2 & \pm & 5.4 \\
\hline Pebble $(16-64 \mathrm{~mm})$ & 13.8 & \pm & 14.6 & 0.5 & \pm & 1.2 & 2.1 & \pm & 4.7 & 2.7 & \pm & 4.0 & 2.1 & \pm & 4.7 & 0.0 & \pm & 0.0 \\
\hline Gravel (4-16 mm) & 22.0 & \pm & 6.5 & 19.3 & \pm & 5.1 & 16.3 & \pm & 3.1 & 19.8 & \pm & 8.0 & 16.5 & \pm & 10.5 & 3.6 & \pm & 2. \\
\hline Coarse sand $(0.5-4 \mathrm{~mm})$ & 54.8 & \pm & 16.4 & 70.3 & \pm & 7.2 & 69.1 & \pm & 5.0 & 68.1 & \pm & 9.4 & 76.3 & \pm & 16.4 & 81.8 & \pm & 13.1 \\
\hline Medium & 7.7 & \pm & 3.7 & 8.4 & \pm & 2.9 & 9.3 & \pm & 2.5 & 7.5 & \pm & 2.3 & 3.6 & \pm & 3.5 & 10.9 & \pm & \\
\hline Fine & 1.6 & \pm & 0.9 & 1.4 & \pm & 0.9 & 2.6 & \pm & 1.3 & 1.5 & \pm & 0.7 & 1.3 & \pm & 1.3 & 3.5 & \pm & 2. \\
\hline Silt and clay $(<0.0625 \mathrm{~mm})$ & 0.1 & \pm & 0.1 & 0.1 & \pm & 0.1 & 0.6 & \pm & 0.3 & 0.4 & \pm & 0.3 & 0.3 & \pm & 0.3 & 0.2 & \pm & 0 . \\
\hline Emergent macrophytes & & 0 & & & 0 & & & 1 & & & 1 & & & 4 & & & 3 & \\
\hline
\end{tabular}

and community structure with environmental variables. CCA ordination was carried out with all samples together (low and high water period). An unrestricted random Monte Carlo permutation test with 199 permutations was performed to determine the statistical significance of environmental variables and canonical axes $(P \leq 0.05)$. All species data were $\ln (y+1)$ transformed prior to analyses. The environmental variables considered in the CCA were flow velocity, water depth, substratum size, and cover percentage of instream aquatic vegetation. The variable coarse sand presented high correlation coefficient with other variables (variance inflation factor $>20$ ) then it was removed. CCA were performed, using the statistical package CANOCO version 4.02 (Ter Braak and Šmilauer, 1998).

Biological data were analyzed considering the different functional habitats obtained by TWINSPAN in terms of the main biotic attributes: abundance, taxonomic richness, Shannon diversity and evenness. Taxonomic richness was used instead of species richness (Malmquist et al., 2000) because not all the identifications were made at species level. The benthic assemblage characteristic of each functional habitat was determined by the Relative Preference Index (RPI) (Tickner et al., 2000), calculated by dividing the abundance of each taxon in a certain habitat by the total abundance of that taxon registered in all the habitats. All samples collected were used in this analysis.

Factorial analysis of variance (factors: hydrological period, site and habitat) followed by Student-NewmanKeuls (SNK) test was performed to analyze differences in biological variables among functional habitats obtained by TWINSPAN analysis. Before ANOVA, the ShapiroWilk test was carried out to assess the normality on the model's residuals; the diversity and richness data were normally distributed, and abundance and evenness were $\log 10 y$ and $y^{2}$ transformed respectively.

\section{Results}

Coarse sand was the dominant substrate particle and represented more in than $50 \%$ of all mesohabitats but the remaining environmental variables allowed the characterization of the potential habitats. Mean values of environmental variables measured in each potential habitat are summarized in Table 1.

A total of 73 macroinvertebrate taxa were identified from the three sites in the six potential habitats; $12 \%$ belonged to Baetidae (Ephemeroptera) and 78\% to Chironomidae (Diptera). Paracloeodes sp. was the most frequent taxon (75\% frequency of occurrence) and Polypedilum sp. was the most abundant $(48 \%$ of the total abundance), although its density in individual samples was highly variable.

No clear groupings were revealed by the TWINSPAN classification based on composition and abundance of benthic community in the high water period (Fig. 3A). Nevertheless, the analysis performed with the low water period data set showed a grouping tendency of the samples (Fig. 3B). The first hierarchical splitting of TWINSPAN showed two main groups, one of them grouped mainly samples from the vegetated channel in the site $2\left(\mathrm{VCH}^{*}\right)$ and in the other, the subsequent divisions reduced the six potential habitats to three functional habitats: the vegetated channels $(\mathrm{VCH})$; habitats associated to bars $(\mathrm{BH})$ and finally unvegetated channels (UCH). With the exception of the group $\mathrm{VCH}^{*}$ which grouped samples from the same site, the analysis showed a tendency to classify samples mainly in relation to habitats rather than sites. The VCH functional habitat included 9 samples most of them collected from vegetated secondary channels (vc) and vegetated secondary channels in calcrete river bank (cc), characterized by medium and high depth and flow velocity, and medium substrate size. The characteristic benthic association of this functional habitat was constituted by Pristina sp., Lumbricidae, Metrichia sp., Dolichopodidae, Empididae, Thienemannimyia sp., Thieniemaniella sp., and Parametriocnemus sp. The UCH functional habitat included 8 samples most of them collected in unvegetated channels (uc), characterized by the largest substrate size, depth, and flow velocity, exhibit the lowest density values and the most frequent taxa were Nais sp., Paracloeodes sp., Orthocladius sp. and Paratrichocladius sp. The $\mathrm{BH}$ functional habitats included 25 samples most of them taken from secondary channels with highly mobile 

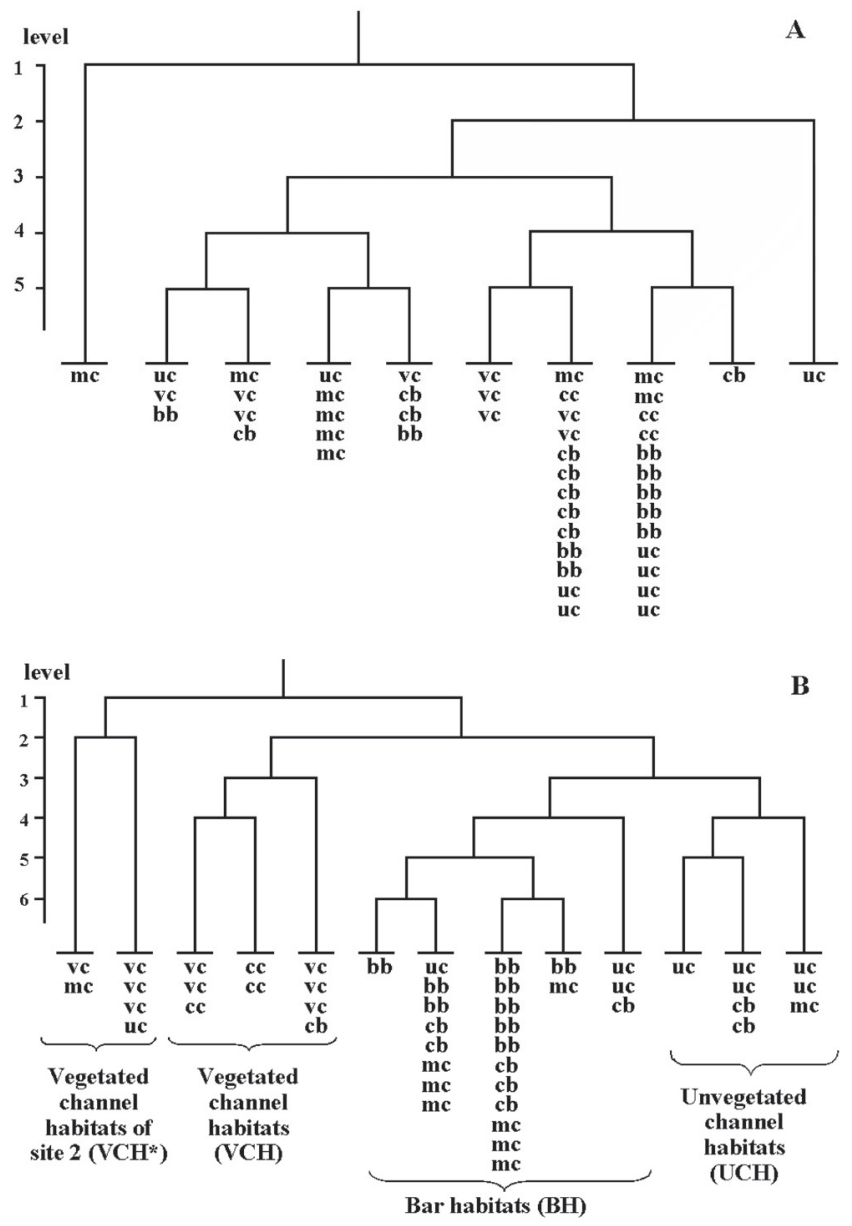

Fig. 3. Dendrograms showing results of the TWINSPAN analysis performed with the high water period data set (A) and with the low water period data set (B). Samples considered in the analysis were taken from the six potential habitats (see Fig. 2 legend for key to habitat abbreviations).

substrate (mc), backwaters in bars (bb) and channels in bars (cb). All these habitat units presented low depth values and finer substrate. The macroinvertebrate assemblages in these functional habitats were dominated by Dugesidae, Allonais sp., Homochaeta sp., Limonidae and Chironomidae pupae.

The CCA ordination of the benthic samples (Fig. 4A, Table 2) showed a significant relationship (Monte Carlo test, $P<0.05)$ between invertebrate assemblages and the selected environmental variables. The ordination diagram showed a trend of grouping samples in relation to the three functional habitats identified by TWINSPAN. The first four canonical axes explained $19.9 \%$ of the species data and $70.4 \%$ of the species environment relationship. The first axis ordination highlighted the differences between unvegetated ( $\mathrm{UCH}$ and $\mathrm{BH})$ and vegetated $(\mathrm{VCH})$ functional habitats, mainly based on substrate variation and the presence of macrophytes. On the right side of the plot samples related to finer substrate were; whereas on the left side samples related with coarser substrate habitats were located. Flow velocity, depth and substrate
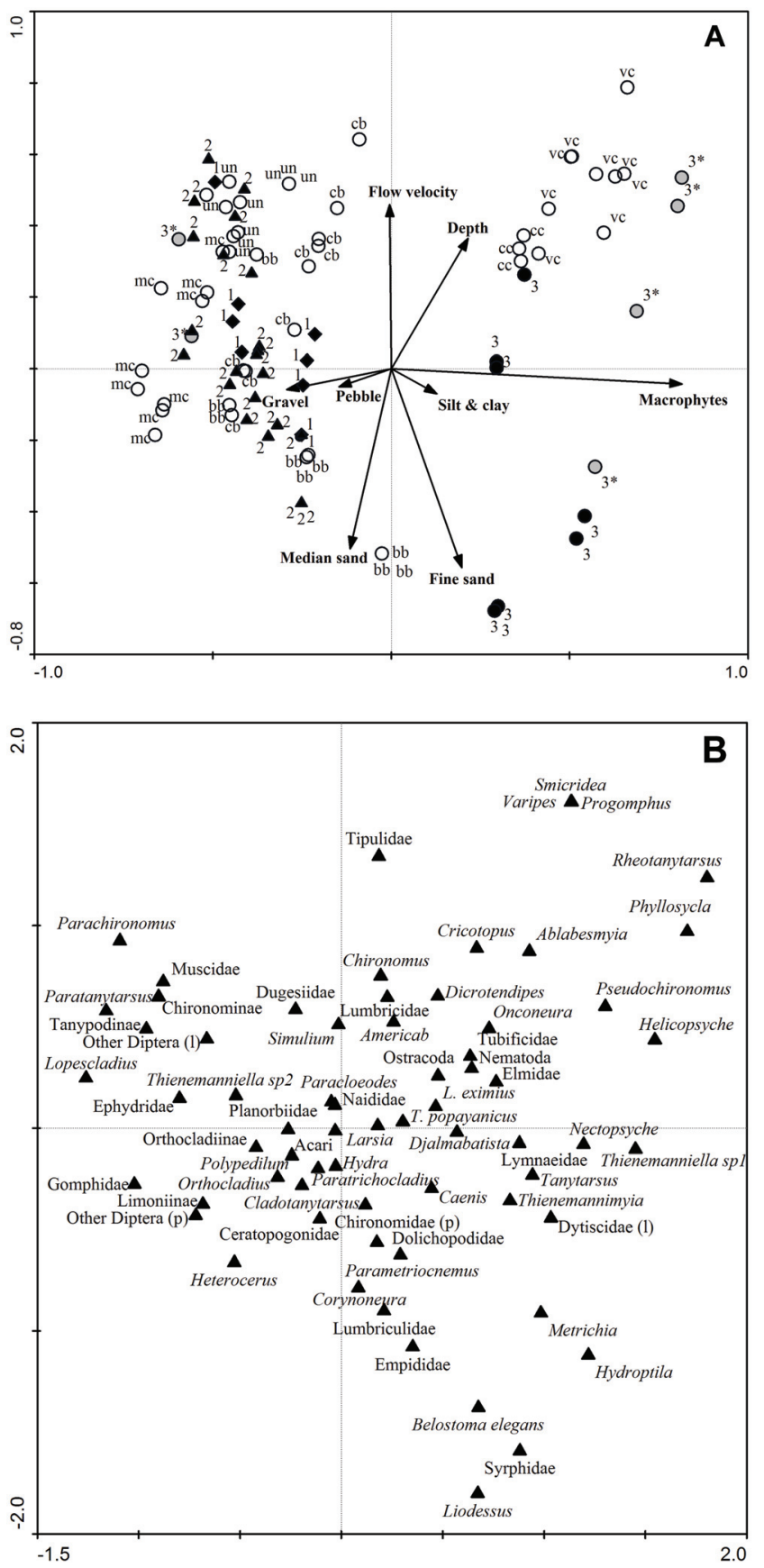

Fig. 4. Canonical Correspondence Analysis (CCA) in the Chocancharava River: (A) biplot of 96 benthic samples in relation to environmental variables. White circles represent samples from high water period, which are named according to the potential habitat (abbreviations as Fig. 2). Black symbols represent samples from low water period which are named according to the functional habitats obtained by TWINSPAN: unvegetated channel habitat (1, diamonds); bar habitat (2, triangles); and vegetated channel habitat ( 3 , circles) and vegetated channel habitat of site 2 (3*, grayish circles). (B) Plot of macroinvertebrate taxa. Letters $l$ and $p$ between brackets refer to larvae and pupae respectively.

of medium grain size were strongly associated with the second axis. In the upper part of the diagram, samples 
Table 2. Summary of CCA eigenvalues, cumulative percent of variance, significance of canonical axes and environmental variables tested by Monte Carlo permutation test.

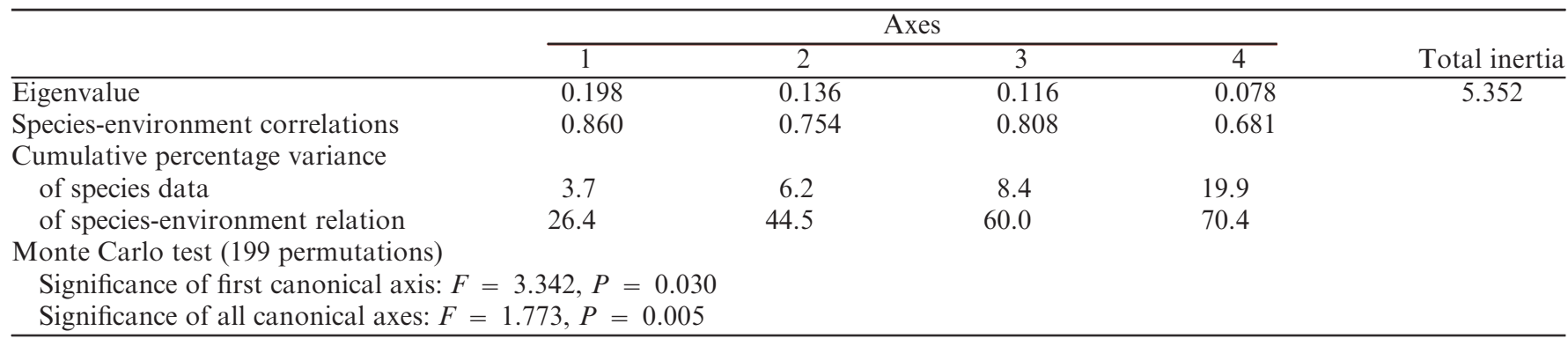

Table 3. Benthic macroinvertebrates associated with each functional habitat and their Relative Preference Index (RPI). UCH: unvegetated channel habitats; $\mathrm{BH}$ : bar habitats; VCH: vegetated channel habitats. Only taxa with RPI $>0.40$ are shown.

\begin{tabular}{|c|c|c|c|c|c|c|c|}
\hline \multicolumn{8}{|c|}{ Functional habitats } \\
\hline \multicolumn{2}{|l|}{$\overline{\mathrm{UCH}}$} & \multicolumn{2}{|l|}{$\mathrm{BH}$} & \multicolumn{4}{|c|}{$\mathrm{VCH}$} \\
\hline Taxon & RPI & Taxon & RPI & Taxon & RPI & Taxon & RPI \\
\hline Planorbidae & 0.67 & Hydra sp. & 0.50 & Dugesiidae & 0.69 & Liodesus sp. & 1.00 \\
\hline Homochaeta sp. & 0.43 & Ophidonais sp. & 1.00 & Pristina sp. & 0.87 & Elmidae & 0.62 \\
\hline Tipulidae & 0.50 & Pristinella sp. & 1.00 & Dero (Dero) sp. & 1.00 & Dicrotendipes sp. & 0.65 \\
\hline Simulium sp. & 0.64 & Heterocerus sp. & 1.00 & Allonais sp. & 0.97 & Rheotanytarsus sp. & 1.00 \\
\hline Tanypodinae & 1.00 & Limonidae & 1.00 & Slavina sp. & 1.00 & Pseudochironomus sp. & 0.95 \\
\hline Corynoneura sp. & 0.50 & Ceratopogonidae & 0.70 & Stephensoniana sp. & 0.86 & Djalmabatista sp. & 0.87 \\
\hline Lopescladius sp. & 1.00 & Polypedilum sp. & 0.49 & Tubificidae & 0.98 & Ablabesmyia sp. & 1.00 \\
\hline Ephydridae & 0.50 & Parachironomus sp. & 1.00 & Paracloeodes sp. & 0.70 & Larsia sp. & 0.67 \\
\hline & & Chironomus sp. & 0.67 & Varipes $\mathrm{sp}$. & 1.00 & Thienemannimyia sp. & 0.96 \\
\hline & & Paratanytarsus sp. & 1.00 & Caenis sp. & 0.80 & Thienemanniella sp. & 0.90 \\
\hline & & Orthocladiinae sp. 1 & 0.55 & Leptohyphes eximius Eaton & 0.72 & Onconeura sp. & 0.90 \\
\hline & & Orthocladiinae sp. 2 & 0.51 & Tricorythodes popayanicus Dominguez & 0.75 & Cricotopus sp. & 0.72 \\
\hline & & Chironomidae & 0.54 & Phyllocycla sp. & 1.00 & Paratrichocladius sp. & 0.94 \\
\hline & & Muscidae & 0.71 & Progomphus sp. & 1.00 & Orthocladius sp. & 0.58 \\
\hline & & & & Belostoma elegans (Mayr) & 1.00 & Parametriocnemus sp. & 0.87 \\
\hline & & & & Smicridea sp. & 1.00 & Empididae & 0.96 \\
\hline & & & & Metrichia sp. & 1.00 & Dolichopodidae & 0.88 \\
\hline & & & & Hydroptila sp. & 1.00 & Syrphidae & 1.00 \\
\hline & & & & Nectopsyche sp. & 1.00 & & \\
\hline & & & & Helicopsyche sp. & 1.00 & & \\
\hline
\end{tabular}

collected during the high water period were located, while those of low water period were mainly placed in the lower quadrants. The six samples belonging to the $\mathrm{VCH}^{*}$ group defined by TWINSPAN were scattered in three quadrants of the ordination.

The CCA associated macroinvertebrate assemblages with each functional habitat (Fig. 4B). The characteristic assemblage of each functional habitat showed concordance with the Relative Preference Index (RPI). RPI values, calculated for each taxon in each functional habitat, ranged from zero to one. The higher the RPI value the higher the preference of the taxon for a particular habitat (Table 3). According to the RPI the characteristic fauna in the UCH functional habitat was the chironomids Lopescladius sp. and Tanypodinae. The characteristic taxa of the $\mathrm{BH}$ functional habitat were Ophidonais sp., Pristinella sp., Heterocerus sp., Parachironomus sp., Paratanytarsus sp., Chironomus sp., Limoninae and Ceratopogonidae. Moreover, in habitats related with bars the largest abundance of Diptera pupae was observed. Benthic association in the $\mathrm{VCH}$ functional habitats was constituted by 15 exclusive taxa. High densities of oligochaetes and chironomids were registered in these vegetated habitats, and this habitat type was the only one that presented high densities of mayflies, dragonflies, bugs and caddishflies (Table 3).

The results of the three-way ANOVA showed significant effects of the hydrological period and habitat on benthic community attributes (Table 4). The analysis revealed that abundance depended on the hydrological period and the habitat, taxonomic richness was influenced by the joint effect of hydrological period-habitat and diversity showed dependence of the hydrological period. The smallest values of benthic community attributes were found in the high water period (Fig. 5). At low water period abundance and taxonomic richness greatly varied among functional habitats and were higher in $\mathrm{VCH}$ functional habitats (Fig. 5). The highest Shannon diversity were found in $\mathrm{UCH}$ and $\mathrm{VCH}$ and the lowest values were registered in $\mathrm{BH}$ functional habitats. The highest values 
Table 4. Results of the three-way ANOVA which evaluated the effects of period, site, habitat and interaction terms on benthic community attributes. Significant $P$ values are in bold.

\begin{tabular}{|c|c|c|c|}
\hline Source of variation & $\mathrm{df}$ & $F$ & $P$ \\
\hline \multicolumn{4}{|l|}{ Abundance } \\
\hline Hydrological period & 1 & 46.73 & $<0.0001$ \\
\hline Site & 2 & 1.67 & 0.1952 \\
\hline Habitat & 2 & 10.89 & $<0.0001$ \\
\hline Period $*$ Site & 2 & 1.72 & 0.1856 \\
\hline Period $*$ Habitat & 2 & 0.94 & 0.3960 \\
\hline Site*Habitat & 4 & 0.89 & 0.4733 \\
\hline Period $*$ Site $*$ Habitat & 3 & 0.70 & 0.5556 \\
\hline \multicolumn{4}{|l|}{ Taxonomic richness } \\
\hline Hydrological period & 1 & 68.45 & $<0.0001$ \\
\hline Site & 2 & 0.97 & 0.3826 \\
\hline Habitat & 2 & 30.00 & $<0.0001$ \\
\hline Period $*$ Site & 2 & 1.38 & 0.2586 \\
\hline Period*Habitat & 2 & 7.36 & 0.0012 \\
\hline Site*Habitat & 4 & 0.33 & 0.8570 \\
\hline Period $*$ Site $*$ Habitat & 3 & 1.44 & 0.2370 \\
\hline \multicolumn{4}{|l|}{ Diversity } \\
\hline Hydrological period & 1 & 33.31 & $<0.0001$ \\
\hline Site & 2 & 0.89 & 0.4161 \\
\hline Habitat & 2 & 4.14 & 0.0196 \\
\hline Period $*$ Site & 2 & 0.59 & 0.5574 \\
\hline Period $*$ Habitat & 2 & 1.16 & 0.3200 \\
\hline Site*Habitat & 4 & 2.27 & 0.0691 \\
\hline Period $*$ Site $*$ Habitat & 3 & 2.52 & 0.0639 \\
\hline \multicolumn{4}{|l|}{ Evenness } \\
\hline Hydrological period & 1 & 0.93 & 0.3379 \\
\hline Site & 2 & 1.00 & 0.3737 \\
\hline Habitat & 2 & 2.49 & 0.0894 \\
\hline Period $*$ Site & 2 & 2.29 & 0.1075 \\
\hline Period*Habitat & 2 & 0.29 & 0.7461 \\
\hline Site*Habitat & 4 & 1.06 & 0.3799 \\
\hline Period $*$ Site $*$ Habitat & 3 & 1.22 & 0.3091 \\
\hline
\end{tabular}

of evenness were found in the UCH functional habitats. However, no significant differences were found for evenness and the study site did not have effect on community attributes.

\section{Discussion}

Though geomorphic knowledge of braided rivers is quite abundant, only scattered information is available on their ecology (Tockner et al., 2006). Braided rivers are important areas for conservation and restoration since they contain a wide variety of habitats with varying macroinvertebrate assemblages. One of the dilemmas in designing macroinvertebrate biomonitoring is to identify the different habitats and their spatio-temporal boundaries. In the field, stream ecologists deal with the difficulty of discerning which the different habitat units are and which their limits are, when carrying out the sampling. A simple and widespread way of handling the problem is to select recognizable habitat units by visual survey, with
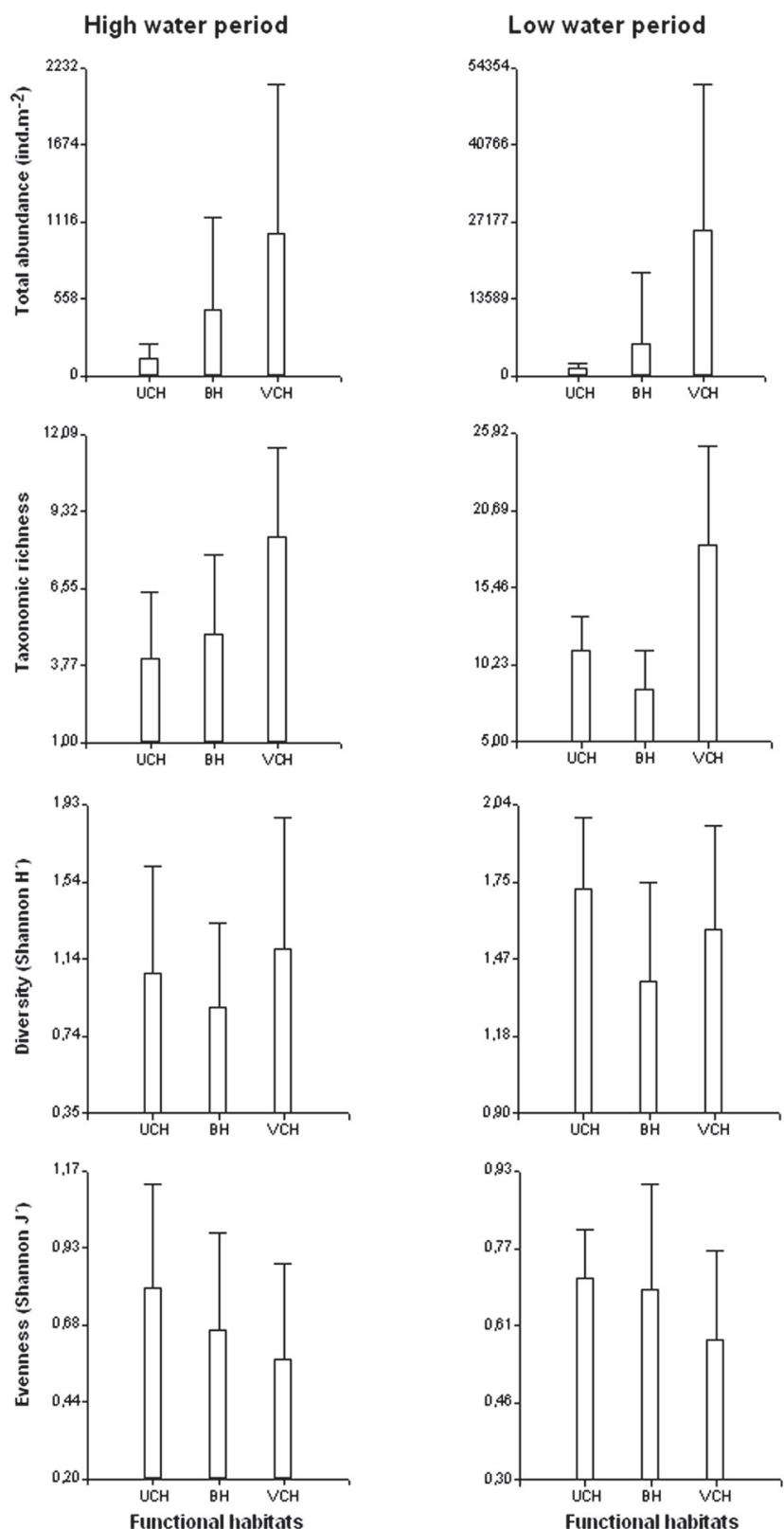

Fig. 5. Mean values $(+\mathrm{SD})$ of total abundance, taxonomic richness, diversity and evenness in the functional habitats (UCH: unvegetated channel habitat; $\mathrm{BH}$ : bar habitat; $\mathrm{VCH}$ : vegetated channel habitat) at high and low water periods.

apparent differences in flow, depth, vegetation and substrate type (Vadas and Orth, 1998; Brunke et al., 2001).

In this study, the visual surveys allowed to determine six instream habitat units, which were considered potential habitats. These potential habitats were characterized based on different environmental variables. In some situations it was difficult to place a habitat into the potential habitat classification because the values of many variables overlapped among the habitat units. The hydraulic units of a fluvial reach differ in their physical structure, and preliminary studies of functional habitat found that the different habitats have different optima in terms of depth and velocity (Harper et al., 1995; Kemp et al., 1999). 
Our results showed that in the braided reach of the Chocancharava River there are functional habitats with different hydraulic conditions that can be identified during low water periods, but become quite unrecognizable (from the biological point of view) during high water periods. TWINSPAN classification, based on species data of the low water period allowed distinguishing three functional habitats. CANOCO ordination analysis, carried out with macroinvertebrate data and environmental variables of the low and high water period, also showed a tendency of grouping samples in relation to functional habitats determined by TWINSPAN. The most influential environmental variables in the ordination analysis were flow velocity, depth, substrate size and rooted emergent macrophytes. The analysis of community attributes also indicated that abundance and diversity depended on the habitat type and the hydrological period.

Instream habitat structure and substrate composition have been shown to be the dominant factors influencing the distribution of invertebrate taxa in many fluvial systems (Harper et al., 1995) and distinctive faunal assemblages may be associated with each habitat unit (Pardo and Armitage, 1997). Moreover, current velocity and substrate have been identified by many authors as major factors controlling the occurrence of benthic organisms (Statzner et al., 1988; Gordon et al., 1992).

In this study, each functional habitat was inhabited by a distinct invertebrate assemblage. Furthermore, when the functional habitats identified by TWINSPAN are applied to the whole data set of samples even to the samples from the high water period we found significant differences in community attributes (abundance, taxonomic richness, diversity and evenness) among these functional habitats. The maximum taxonomic richness, diversity and abundance occurred in vegetated channels. Relative Preference Index showed that each functional habitat was characterized by a different association of benthic macroinvertebrates. Odonata, Hemiptera, Trichoptera and some Ephemeroptera and Coleoptera species were only collected in vegetated channels. Dipterans larvae and pupae, mainly quironomids, and oligochaetes were the most conspicuous inhabitants in the bar habitats. These habitat units, characterized by fine substrate and low depth and flow velocity are highly dynamic habitats. Bars constantly change in form or location and benthic fauna is constantly resuspended and transported to downstream reaches. In these sites, the reduction of current velocity during the bar construction allows the accumulation of fine organic matter which is largely the food resource of collectors and detritivores. These environmental conditions, favour the settlement of generalist and tolerant organism such as chironomids, and oligochaetes and the downstream drift. Tockner et al. (2006) pointed out that bar areas are constantly undergoing shrinking and expansion with desiccation and movement, resulting in faunal losses and recolonization. Unvegetated habitats with very unstable bed, presented the lowest diversity and the associated biota was constituted by some dipterans larvae, mainly chironomids. This agrees with other studies which found that the high instability of the substrate and the low organic matter availability lead to a low diversity and richness (Hawkins, 1984).

It has been demonstrated for tropical and temperate regions that stream habitat diversity diminish as a result of the spatial homogenization produced by high discharge (Thomaz et al., 2007). Our results showed that no distinct functional habitats could be defined by TWINSPAN classification based on high water period data. However, the groups obtained with the classification of the samples from the low water period can be also used to recognize habitat units during high water periods.

The Chocancharava River exhibits a flow regime with annual cycles of low and high water hydrological periods (Degiovanni et al., 1995). During the low water period the habitat units are more stable and ecosystem fragmentation is larger, but during the rainy season the high discharge and the consequential substrate movement lead to habitat homogeneity affecting habitat availability for benthic communities. High discharge blends benthic fauna and increases downstream drift making difficult the settlement of transporting fauna from upstream reaches. Braided rivers has been considered to be hostile environments because they are dynamic systems shaped by frequent floods and periods of water stress, and the expansioncontraction annual cycles determined by floods produce a high degree of habitat turnover (Tockner et al., 2006).

Hydrological variability in lotic ecosystems is one of the main factors controlling benthos distribution (Townsend et al., 1987) and, as it is established by the templet habitat concept biotic, communities are largely influenced by local stream habitat conditions (Townsend and Hildrew, 1994; Townsend et al., 1997). Life history has been considered to be important in determining the distribution of invertebrates within a habitat (Reich and Downes, 2003). Then differences in abundance and distribution of macrobenthos between low and high water period may be due to life cycle adaptations associated with the dynamic nature of braided rivers. Similar results were obtained by Sanches Melo and Froehlich (2001) who investigated macroinvertebrate richness in 10 streams of different size in a Brazilian catchment. These authors found that macroinvertebrate assemblage structure is more stable during the dry season than during the rainy season when natural spates are frequent. High richness and diversity were also found during the dry season by Baptista et al. (2001), possibly due to a higher habitat stability and availability. In streams a source of disturbance is substrate movement associated with high discharge (Gjerlov et al., 2003). The spates may increase benthic invertebrate mortality, but communities exhibit resilience and the benthos rapidly recolonized denuded habitats after disturbance.

Vegetated channels, which were the most diverse functional habitats in the Chocancharava River, are in general less affected by water flow and may constitute refuge places (Ward, 1989; Robinson et al., 2002), from where washed habitats can be rapidly recolonized and thus assure faunal persistence. Submerged macrophytes 
are of particular importance in aquatic ecosystems, especially in lowland stream reaches (Pedersen, 2003). They represent complex habitats (Hiromi et al., 2003), and the heterogeneity generated by submerged plants are known to influence the structure and diversity of invertebrate communities (Ward, 1992). The aquatic plants provide habitats that invertebrates may colonize, offer sites for attachment, generate refuges from high flow conditions and predators and supply food to aquatic fauna through detritus trapping (part of the plant or its associated periphyton) (Hiromi et al., 2003; Pedersen, 2003). Pedersen (2003) also showed that macrophytes play a key-role in the ecology of lowland streams and indicated that macrophytes in combination with physical variables could be used as habitat indicators.

In this study the results showed that multivariate ordination and classification analysis allowed the identification of three functional habitats in a braided reach whereas visual assessment resulted in at least six potential habitats. The identified functional habitats presented distinct physical features and characteristic invertebrate assemblages. In agreement with other research carried out at the mesohabitat scale (Brunke et al., 2001) we recommend the functional habitat approach, because may provide useful tools in management (Harper and Everard, 1998) and river rehabilitation (Kemp et al., 1999). The identification of functional habitats in lotic systems with periodic flow variations such as the Chocancharava River has practical consequences for management and biomonitoring. Consequently, monitoring and restoration programs should be designed on the base of the functional habitats defined during low water periods. In monitoring programs or river management schemes the characterization of an environment in terms of functional habitats is not only ecologically more sensitive but also is a relatively more rapid procedure. This methodology allows economizing time and effort at lower cost without losing important information.

Future research on braided rivers should focus on the connectivity of potential habitats between vertical and lateral dimension. In braided systems hyporheic and parafluvial zones have a functional role in the exchange of organic matter and nutrients and may offer refugia for benthic organisms, thereby contributing to the resilience of the hydrosystem at a large scale.

Acknowledgements. The research presented in this paper was supported by Secretaría de Ciencia y Técnica (SeCyT), Universidad Nacional de Río Cuarto, Córdoba, Argentina. We also thank two anonymous referees for their comments on the manuscript whose suggestions strongly improved the quality of this manuscript.

\section{References}

Amoros C., Roux A.L., Reygrobellet J.L., Bravard J.P. and Pautou G., 1987. A method for applied ecological studies of fluvial hydrosystems. Regul. Riv. Res. Manage., 1, 17-36.
Armitage P.D. and Pardo I., 1995. Impact assessment of regulation at the reach level using macroinvertebrate information from mesohabitats. Regul. Riv. Res. Manage., 10, 147-158.

Baptist M.J., 2001. Review on biogeomorphology in rivers: processes and scales, CFR report 3, Delft University of Technology, Delft.

Baptista D.F., Buss D.F., Dorvillé L.F.M. and Nessimian J.L., 2001. Diversity and habitat preference of aquatic insects along the longitudinal gradient of the Macaé River basin, Rio de Janeiro, Brazil. Rev. Brasil. Biol., 61, 249-258.

Boccolini M.F., Oberto A.M. and Corigliano M.C., 2005. Calidad ambiental en un río urbano de llanura. Biol. Acuática, 22, 59-69.

Brooks A.J., Haeusler T., Reinfelds I. and Williams S., 2005. Hydraulic microhabitats and the distribution of macroinvertebrate assemblages in riffles. Freshwat. Biol., 50, 331344.

Brunke M., Hoffmann A. and Pusch M., 2001. Use of mesohabitat-specific relationships between flow velocity and river discharge to assess invertebrate minimum flow requirements. Aquatic Conserv. Mar. Freshw. Ecosyst., 17, 667-676.

Buffagni A., Crosa G.A., Harper D.M. and Kemp J.L., 2000. Using macroinvertebrate species assemblages to identify river channel habitat units: an application of the functional habitats concept to a large, unpolluted Italian river (River Ticino, northern Italy). Hydrobiologia, 435, 213-225.

Corigliano M.C., Gualdoni C.M. and Oberto A.M., 1987. Deriva de macroinvertebrados en un tramo anastomosado de un río de llanura. Rev. UNRC, 7, 89-98.

Crosa G. and Buffagni A., 1996. L'habitat idraulico quale elemento per la gestione degli ambienti fluviali. S. It. E. Atti., 17, 581-583.

Davies N.M., Norris R.H. and Thoms M., 2000. Prediction and assessment of local stream habitat features using large-scale catchment characteristics. Freshwat. Biol., 45, 343-369.

Degiovanni S.B., Villegas S.M. and Doffo N., 1995. Propuesta de ordenamiento territorial en el tramo urbano del río Cuarto sobre la base del análisis del riesgo de erosión de márgenes. In: Blarasin M., Degiovanni S., Cabrera A. and Villegas M. (eds.), Problemática Geoambiental y Desarrollo Sustentable, Universidad Nacional de Río Cuarto, Río Cuarto, 447-467.

Fernández H.R. and Domínguez E. (eds.), 2001. Guía para la determinación de los artrópodos bentónicos sudamericanos, Universidad Nacional de Tucumán, Facultad de Ciencias Naturales e Instituto M. Lillo, Tucumán, 282 p.

Frissell C.A., Liss W.J., Warren C.E. and Hurley M.S., 1986. A hierarchical framework for stream habitat classification: viewing streams in a watershed context. Environ. Manage., 10, 199-214.

Gauch H.G., 1982. Multivariate analysis in community ecology, Cambridge, England, Cambridge University Press, 298 p.

Gjerlov C., Hildrew A.G. and Jones J.I., 2003. Mobility of stream invertebrates in relation to disturbance and refugia: a test of habitat templet theory. J. N. Am. Benthol. Soc., 22, 207-223.

Gordon N.D., McMahon T.A. and Finlayson B.L., 1992. Stream hydrology. An introduction for ecologist, Wiley and Sons, New York, 526 p.

Halwas K.L. and Church M., 2005. Benthic assemblage variation among channel units in high-gradient streams on Vancouver 
Island, British Columbia. J. N. Am. Benthol. Soc., 24, 478-494.

Harper D. and Everard M., 1998. Why should the habitat-level approach underpin holistic river survey and management? Aquatic Conserv. Mar. Freshw. Ecosyst., 8, 395-413.

Harper D.M., Smith C.D. and Barham P.J., 1992. Habitat as the building blocks for river conservation assessment. In: Boon P.J., Calow P. and Petts G.E. (eds.), River Conservation and Management, Wiley and Sons, Chichester, 311-319.

Harper D.M., Smith C., Barham P. and Howell R., 1995. The ecological basis for the management of the natural river environment. In: Harper D.M. and Ferguson A.J. (eds.), The ecological basis for river management, John Wiley and Sons, Chichester, 219-238.

Hawkins C.P., 1984. Substrate associations and longitudinal distributions in species of Ephemerellidae (Ephemeroptera: Insecta) from western Oregon. Freshwat. Invert. Biol., 3, 181-188.

Hawkins C.P., Kershner J.L, Bisson P.A., Bryant M.D., Decker L.M., Gregory S.V., McCulloch D.A., Overton C.K., Reeves G.H., Steedman R.J. and Young M.K., 1993. A hierarchical approach to classifying stream habitat features. Fisheries, 18 , 3-12.

Hill M.O., 1979. TWINSPAN. A Fortran program for arranging multivariate data in an ordered two-way table by classification of the individuals and attributes, Cornell University, Ithaca, New York.

Hiromi T., Nakano S. and Tokeshi M., 2003. Influences of habitat complexity on the diversity and abundance of epiphytic invertebrates on plants. Freshwat. Biol., 48, 718-728.

Hynes H.B.N., 1970. The ecology of running waters, University of Toronto Press, Toronto, $555 \mathrm{p}$.

Kemp J.L., Harper D.M. and Crosa G.A., 1999. Use of 'functional habitats' to link ecology with morphology and hydrology in river rehabilitation. Aquat. Conserv. Mar. Freshw. Ecosyst., 9, 159-178.

Kemp J.L., Harper D.M. and Crosa G.A., 2000. The habitatscale ecohydraulics of rivers. Ecol. Eng., 16, 17-29.

Lopretto E.C. and Tell G., 1995. Ecosistemas de aguas continentales, Metodologías para su estudio, Ediciones Sur, La Plata, 1401 p.

Malmquist H.L., Antonsson T., Gudbergsson G., Skülason S. and Snorrason S.S., 2000. Biodiversity of macroinvertebrates on rocky substrate in the surf zone of iceland lakes. Verh. Internat. Verein. Limnol., 27, 121-127.

Pardo I. and Armitage P.D., 1997. Species assemblages as descriptors of mesohabitats. Hydrobiologia, 344, 111-128.

Pedersen M.L., 2003. Physical structure in lowland streams and effects of disturbance, Ph.D. Thesis, National Environmental Research Institute, Silkeborg, Denmark, 108 p., http://www. dmu.dk/1_Viden/2_Publikationer/3_Ovrige/default.asp.

Principe R.E., Raffaini G.B., Gualdoni C.M., Oberto A.M. and Corigliano M.C., 2007. Do hydraulic units define macroinvertebrate assemblages in mountain streams of central Argentina? Limnologica, 37, 323-336.

Ramírez A., Paaby P., Pringle C.M. and Agüero G., 1998. Effect of habitat type on benthic macroinvertebrates in two lowland tropical streams, Costa Rica. Rev. Biol. Trop., 46, 201-213.

Reich P. and Downes B.J., 2003. The distribution of aquatic invertebrate egg masses. Freshwat. Biol., 48, 1497-1513.

Robinson C.T., Tockner K. and Ward J.V., 2002. The fauna of dynamic riverine landscapes. Freshwat. Biol., 47, 661-677.

Sanches Melo A. and Froehlich C.G., 2001. Macroinvertebrates in neotropical streams: richness patterns along a catchment and assemblage structure between 2 seasons. J. N. Am. Benthol. Soc., 20, 1-16.

Statzner B., Gore J.A. and Resh V.H., 1988. Hydraulic stream ecology: observed patterns and potential applications. $J . N$. Am. Benthol. Soc., 7, 307-360.

Ter Braak C.J.F. and Šmilauer P., 1998. CANOCO Reference Manual and User's Guide to Canoco for Windows: Software for Canonical Community Ordination (version 4), Microcomputer Power, Ithaca, New York, 352 p.

Thomaz S.M, Bini L.M. and Bozelli R.L., 2007. Floods increase similarity among aquatic habitats in river-floodplain systems. Hydrobiologia, 579, 1-13.

Tickner D., Armitage P.D., Bickerton M.A. and Hall K.A., 2000. Assessing stream quality using information on mesohabitat distribution and character. Aquat. Conserv. Mar. Freshw. Ecosyst., 10, 170-196.

Tockner K., Paetzold A., Karaus U., Claret C. and Zettel J., 2006. Ecology of braided rivers. In: Sambroock Smith G.H., Best J.L., Bristow C.S. and Petts G. (eds.), Braided rivers, IAS Special Publication, Blackwell, Oxford.

Townsend C.R. and Hildrew A.G., 1994. Species traits in relation to a habitat templet for river systems. Freshwat. Biol., 31, 265-275.

Townsend C.R., Hildrew A.G. and Schofield K., 1987. Persistence of stream communities in relation to environmental variability. J. Anim. Ecol., 56, 597-613.

Townsend C.R., Arbuckle C.J., Crowl T.A. and Scarsbrook M.R., 1997. The relationship between land use and physicochemistry, food resources and macroinvertebrate communities in tributaries of the Taieri River, New Zealand: a hierarchically scaled approach. Freshwat. Biol., 37, 177191.

Vadas R.L. and Orth D.J., 1998. Use of physical variables to discriminate visually determined mesohabitat types in North American streams. Rivers, 6, 143-159.

Velásquez S.M. and Miserendino M.L., 2003. Habitat type and macroinvertebrate assemblages in low order Patagonian streams. Arch. Hydrobiol., 158, 461-483.

Ward J.V., 1989. The four-dimensional nature of lotic ecosystems. J. N. Am. Benthol. Soc., 8, 2-8.

Ward J.V., 1992. Aquatic Insect Ecology, Wiley and Sons, New York, 438 p. 